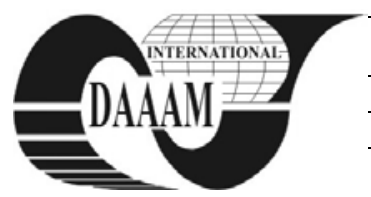

\title{
WETTABILITY OF HIGH-TEMPERATURE BRAZING ALLOYS ON RBSIC CERAMICS
}

\author{
AUGUSTIN, R[obert]; KOLENAK, R[oman]; NERADOVA, M[artina]; KOLENAKOVA, M[onika]; \\ CHACHULA, M[ichal] \& PROVAZNIK, M[artin]
}

\begin{abstract}
Contribution deals with the wettability study of hightemperature Ni-based brazing alloys on RBSiC (reaction bonded silicon carbide) ceramics. Brazing alloy type NI 102, NI 105 and NI 107 were used in experiments. Wetting kinetics was determined. The measurements were performed in vacuum of $10^{-4} \mathrm{~Pa}$. The brazing alloys type NI 105 and NI 107 have wetted the surface of RBSiC ceramics. Very good wettabilty $\left(20^{\circ}<\alpha<40^{\circ}\right)$ was achieved. EDX analysis was also performed on wettability specimens. It was found out that $\mathrm{Ni}$ and Cr from brazing alloy intensively infiltrated into ceramics. Alloying elements of brazing alloy rapidly reacted with free $\mathrm{Si}$ confined between $\alpha$-SiC.
\end{abstract}

Keywords: RBSiC, high temperature Ni-based brazig alloys, high temperature brazing, wetting, EDX

\section{INTRODUCTION}

The SiC-based ceramics belongs to the group of non-oxide progressive ceramics. It is characterised for example with a high wear resistance, high thermal conductivity, low thermal expansion and many other interesting properties. Owing to its unique properties, this material is finding a wide range of applications in almost all industrial branches. There are several technologies for joining SiC-based ceramics. However, joining of the most modern, pores-free, SiC-based ceramics, as for example also type RBSiC, does not allow to produce the joints of desired properties. Therefore the aim of this work was to study the material brazeability of a progressive SiC-based ceramics by use of high-temperature, Ni-based brazing alloys and to propose theoretical basis for improving the brazeability.

\section{MATERIALS AND METHODS}

Experimental ceramics type RBSiC (reaction bonded silicon carbide) was selected from CeramTec GmbH company. Its firm designation is Rocar ${ }^{\circledR} \mathrm{SiF}$. Properties of this ceramics are given in Table 1. Material was supplied in form of solid discs with diameter $15 \mathrm{~mm}$ and $3 \mathrm{~mm}$ height. Its roughness was $\mathrm{Ra}$ 3.2.

\begin{tabular}{|c|c|c|c|c|}
\hline $\begin{array}{c}\text { Density } \\
{\left[\mathrm{g}^{\left.-\mathrm{cm}^{-3}\right]}\right.}\end{array}$ & $\begin{array}{c}\text { Bend } \\
\text { strength } \\
\mathbf{K}_{\mathrm{IC}} \\
{\left[\mathrm{Mpa} \cdot \mathrm{m}^{1 / 2}\right]}\end{array}$ & $\begin{array}{c}\text { Hardness } \\
{[\mathrm{HV}]}\end{array}$ & $\begin{array}{c}\text { Thermal } \\
\text { conductivity } \\
\left.\mathrm{m}^{-1} \mathrm{~K}^{-1}\right]\end{array}$ & $\begin{array}{c}\text { Thermal } \\
\text { expansion } \\
\text { coefficient } \\
{\left[10^{-6} . \mathrm{K}^{-1}\right]}\end{array}$ \\
\hline 3.07 & 4.0 & $\begin{array}{c}1200(\mathrm{Si}) \\
2700(\mathrm{SiC})\end{array}$ & $\begin{array}{c}120 \\
\left(20-100{ }^{\circ} \mathrm{C}\right)\end{array}$ & $\begin{array}{c}4.9 \\
\left(20-1000{ }^{\circ} \mathrm{C}\right)\end{array}$ \\
\hline
\end{tabular}

Tab. 1. Properties of RBSiC ceramics (Rocar® $\mathrm{SiF}$ )

3 high-temperature Ni-based brazing alloys in paste form were selected for experiments. By EN 1044 standard these pastes are designated as NI 102, NI 105 a NI 107. NI 102 (Cr7\%wt. Fe-3\%wt. Si-4.5\%wt. B-3.1\%wt. P-0.02\%wt. C$0.06 \%$ wt. $-\mathrm{Ni}$ ) with optimum brazing temperature $1050{ }^{\circ} \mathrm{C}$. NI 105 (Cr-19\%wt. Si-10.1\%wt. B-0.03\%wt. P-0.02\%wt. C$0.06 \%$ wt. $-\mathrm{Ni}$ ) with optimum brazing temperature $1190{ }^{\circ} \mathrm{C}$. NI 107 (Cr-14\%wt. Fe-0.2\%wt. Si-0.1\%wt. B-0.01\%wt. P-
$10.1 \%$ wt. C-0.06\%wt. -Ni) with optimum brazing temperature $980^{\circ} \mathrm{C}$

All specimens were fabricated in vacuum of $10^{-4}$ Torr. Brazing temperature was in all cases identical with temperature given by the manufacturer as optimum brazing temperature applicable for steels. The wetting angle $\alpha$ was recorded directly during heating by use of experimental equipment from SAV Bratislava - Fig. 1 .

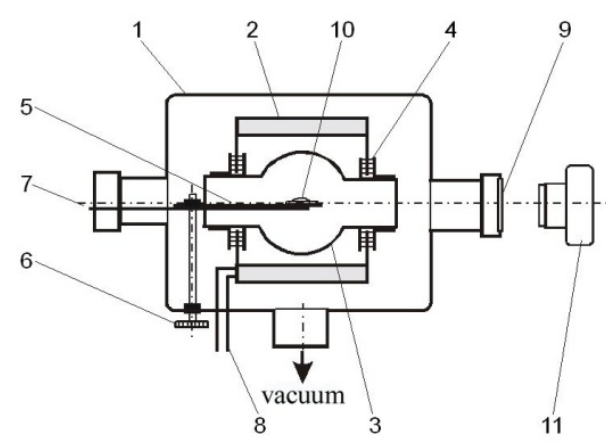

Fig. 1. Schematic representation of apparatus for wetting angle measurement: 1 - vacuum bell, 2 - cooling body of oven, 3 graphite oven, 4 - fastening ceramic pins, 5 - feeder, 6 - feeder control, 7 - thermocouple, 8 - intake and outlet of cooling water, 9 - observance window for photographing, 10 specimen, 11 - photographic camera.

The fabricated specimens were embedded into Varidur, to prevent their damage and then were cut by use of a diamond cutting wheel Buehler ${ }^{\circledR}$ Series 20 HC on equipment Buehler ${ }^{\circledR}$ Isomet 5000. After cutting all specimens were again embedded. Grinding and polishing was performed on a semiautomatic machine Buehler ${ }^{\circledR}$ Phoenix 4000. Grinding was performed with Apex Purple $55 \mu \mathrm{m}$, Apex white $15 \mu \mathrm{m}$, and then the specimens were polished with diamond $9,6,3$ an1 $\mu \mathrm{m}$. EDX analysis was performed on brazing alloy - parent metal (PM) boundary of specimens on JEOL ${ }^{\circledR} 7600 \mathrm{~F}$ equipment.

\section{RESULTS AND DISCUSSION}

\subsection{Wettability}

Wettability is given by the wetting angle $\alpha$, which is included by the tangent to brazing alloy surface and parent metal surface. Is was assessed during the heating phase at optimum temperature at dwell time for 1 to 5 minutes. High-temperature brazing alloys type NI 105 and NI 107 wetted the surface of RBSiC. Fig. 2 shows an example of wettability measurement. The results of measurements are shown in Fig. 3. Wetting angle between the RBSiC substrate and NI 102 brazing alloy could not be assessed, since the brazing alloy did not wet this material. The NI 105 and NI 107 brazing alloys have achieved the second degree of wettability - good to very good wettability $\left(20^{\circ}<\alpha<40^{\circ}\right)$. At the same brazing temperature the used brazing alloys attain usually first degree of wettability on steels $\left(\alpha<20^{\circ}\right)$. In case of NI 105 brazing alloy the best wettability 
was attained at the time of 1 minute and in case of NI 107 brazing alloy at the time of 5 minutes - Fig. 2. However, separation of NI 107 brazing alloy from the PM followed, which was caused due to considerable difference in thermal expansion of materials used.

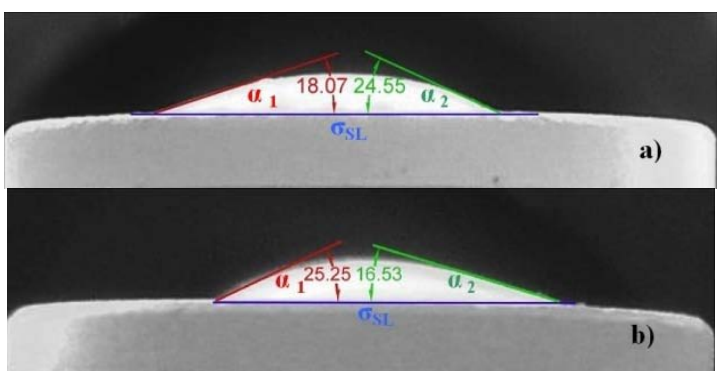

Fig. 2. Wetting angles of RBSiC ceramics $\left(\sigma_{\mathrm{SL}}-\mathrm{PM}\right.$ plane, $\alpha_{1,2}$ - wetting angle): a) NI $1051190{ }^{\circ} \mathrm{C} / 1$ min., b) NI 107 $980^{\circ} \mathrm{C} / 5 \mathrm{~min}$.
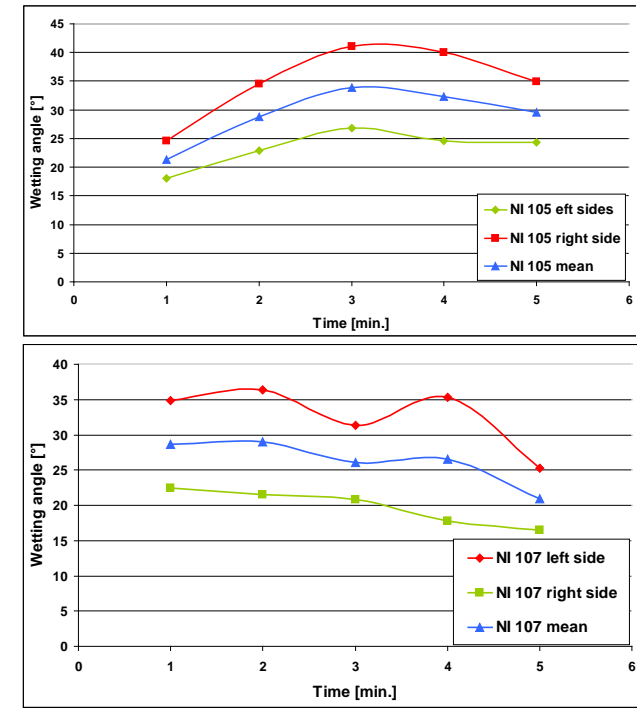

Fig. 3. Wetting angles on RBSiC attained with NI 105 and NI 107 brazing alloys in dependence on dwell time at brazing temperature.

\subsection{Interaction of RBSiC and Ni-based brazing alloy}

Next assessment was performed with the specimens prepared at optimum brazing temperature and 1 minute dwell time. However, due to extremely different properties, mainly the thermal expansion, a significant damage of brazing alloy and parent metal occurred - Fig. 4. Infiltration of brazing alloy into PM attained 2 to 6 times higher value than usual value of brazing alloy diffusion into PM when applied on steels.

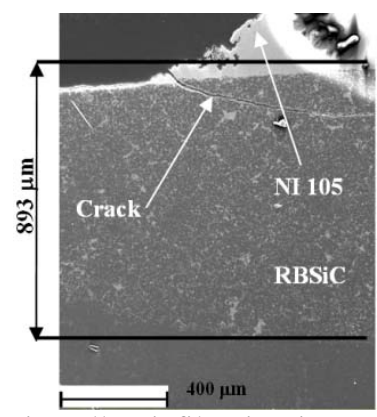

Fig. 4. NI 105 brazing alloy infiltration into RBSIC ceramics and crack formation $\left(1190^{\circ} \mathrm{C} / 1 \mathrm{~min}\right.$.)

Fig. 5 shows an example of EDX analysis. In RBSiC ceramics, tha dark zones of $-\alpha-\mathrm{SiC}$ and lighter zones $-\mathrm{Si}$ can be observed. These zones are typical with considerably lower $\mathrm{Si}$ content compared to $\mathrm{SiC}$ and with an increased $\mathrm{Ni}$ content, which was infiltrated from the brazing alloy. Increased $\mathrm{Cr}$ content from brazing alloy was also observed on the $\alpha$ - SiC boundary.
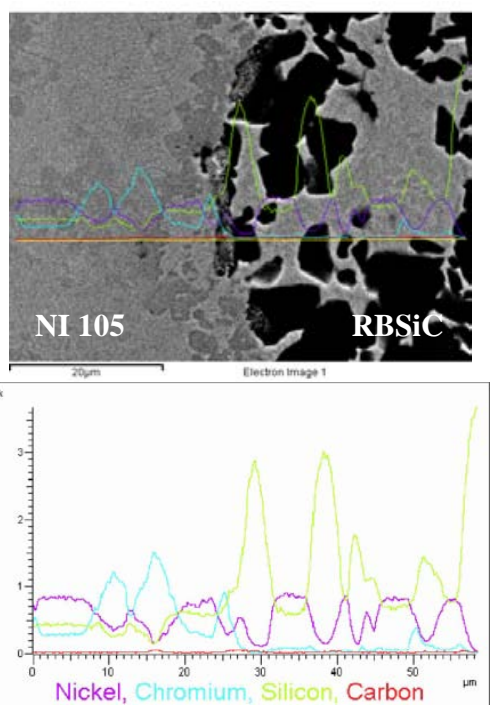

Fig. 5. EDX analysisperfermed on the boundary of RBSiC high-temperature brazing alloy type NI $105-1190{ }^{\circ} \mathrm{C} / 1 \mathrm{~min}$.

\section{CONCLUSIONS}

High-temperature brazing alloys type NI 105 and NI 107 have wetted the surface of RBSiC ceramics while achieving very good wettability. EDX analysis has revealed the $\mathrm{Ni}$ and $\mathrm{Cr}$ from the brazing alloy infiltrated into the zone of free $\mathrm{Si}$ in RBSiC. Brazing alloy type NI 105 was assessed as the most suitable. The highest Ni content in NI 105 resulted in faster saturation of $\mathrm{Ni}-\mathrm{Si}$ phase. In this manner, the depth of infiltration of brazing alloy into RBSiC has reduced and also lower formation of cracks compared to other alloys was observed. However, the joint exerted very low strength. Improved brazeability of RBSiC by application of Ni-based brazing alloys could be achieved by a suitable modification of chemical composition. Application of suitable alloying elements ( $\mathrm{Si}, \mathrm{Cr}, \mathrm{Mo}, \mathrm{Ti})$ should allow the formation of a narrow joint and to prevent the cracking formation.

\section{ACKNOWLEDGEMENTS}

Mária Bachratá, Institute of Materials \& Machine Mechanics, SAV for preparation of specimens. RNDr. Pavol Priputen, PhD. for EDX analysis. The contribution was prepared with the support of VEGA 1/0211/11 project - Development of lead-free solder for higher application temperatures and research of material solderability of metallic and ceramic materials.

\section{REFERENCES}

Riley, F. L. (2009). Structural Ceramic, CUP, ISBN 978-52184586-1, New York

Meyers, M. \& Chawla, K. (2009). Mechanical Behavior of Materials, CUP, ISBN 978-0-521-86675-0, Cambridge

Traugott, F. (2009). Materials Science, Elsevier, ISBN 978-012-373587-4, Canada

Xiong, H. P., Mao, W., Xie, Y. H., Guo, W.L., Li, X.H., Cheng, Y.Y. Brazing of SiC to a wrought nickel-based superalloy using $\mathrm{CoFeNi}(\mathrm{Si}, \mathrm{B}) \mathrm{CrTi}$ filler metal. Available from: http://www.sciencedirect.com/ 2007-03-12

Dong, H., Li, S., Teng, Y., Ma, W. Joining of Sic ceramicbased materials with ternary carbide $\mathrm{Ti}_{3} \mathrm{SiC}_{2}$. Available from: http://www.sciencedirect.com/, 2011-01-15 